\title{
A degradation product of methylene blue
}

\author{
M. John Plater \\ Department of Chemistry, University of Aberdeen, Aberdeen, Scotland AB24 3UE \\ E-mail: m.j.plater@abdn.ac.uk
}

(received 26 Jan 03; accepted 28 Mar 03; published on the web 29 Apr 03)

\begin{abstract}
Treatment of methylene blue (MB) 1 with bromine followed by alkali gives the brominated derivative of methylene violet 4 . Preliminary studies have identified it as a metabolite of MB in humans.
\end{abstract}

Keywords: Methylene blue, metabolite

\section{Introduction}

The dye methylene blue (MB) is widely used as a stain and has a number of biological uses. ${ }^{1-3}$ It can be used to treat urinary tract infections, to distinguish between cancerous and normal tissue ${ }^{4}$ and it has potential as a prophylactic treatment for Alzheimer's disease. ${ }^{5}$ The metabolism and excretion of $\mathrm{MB}$ in living organisms was the subject of a number of investigations the earliest dating back to $1885 .{ }^{6-10}$ Early investigations showed that MB was eliminated from the body in unchanged form as well as in some leuco-dye forms. A detailed investigation was carried out in 1972 which confirmed these studies. ${ }^{1-3}$ It was shown that extracts of urine from human patients dosed with $10 \mathrm{mg}$ samples of MB contained MB but also a leuco-dye form which was converted to $\mathrm{MB}$ upon acidification with $5 \mathrm{~N} \mathrm{HCl}$ followed by boiling for two minutes in water. The increase in UV/VIS absorption at $660 \mathrm{~nm}$ was measured in 1,2-dichloroethane. The structure of the leuco-dye was not determined but these results suggest a leaving group could be attached to the central nitrogen of $\mathrm{MB}$ that can be eliminated upon treatment with acid thus regenerating MB.

\section{Results and Discussion}

The author reasoned that the reduced form of dye might be formed by nucleophilic attack upon the central nitrogen by a good nulceophile such as the thiolate anion of cysteine, cysteine sulphinate, ${ }^{11}$ cyanide, ${ }^{12}$ or the carbanion of vitamin $\mathrm{B}_{1} \cdot{ }^{13}$ Attack here might be favoured because it would allow the two outer benzene rings to aromatise. No products were isolated from these studies although reduced $\mathrm{MB}(\mathrm{MB}-\mathrm{NH})$ was precipitated using cysteine and alkali. Exposure to 
air instantly regenerates MB. It can easily be formed in situ by treatment of $\mathrm{MB}$ in methanol with $\mathrm{NaBH}_{4}$ and observed by TLC. The central nitrogen of MB is electron deficient ${ }^{14}$ but it is also hindered by the two peri hydrogens making nucleophilic attack difficult. However it was observed that if $\mathrm{MB}$ in water was treated with alkali and either ether or $\mathrm{CH}_{2} \mathrm{Cl}_{2}$ the organic layer turned red. The red solution immediately turned blue when spotted onto a TLC plate suggesting that if an $\mathrm{MB}-\mathrm{OH}$ adduct had been formed it was very unstable and acid sensitive (scheme 1). ${ }^{15}$<smiles>CN=c1ccc2nc3ccc(N(C)C)cc3sc-2c1</smiles>

$1(\mathrm{MB})$<smiles>O=CCCO</smiles><smiles>C/C=C(/C=C/N(C)C)Sc1cccc(N(C)C)c1</smiles>

2

\section{Scheme 1}

It was then decided to try and increase the electron deficiency of MB by oxidising the sulphur atom to an S-oxide. The oxidation of MB has been studied previously ${ }^{\mathbf{1 6}}$. MB was treated with one equivalent of bromine in $\mathrm{MeOH}: \mathrm{H}_{2} \mathrm{O}(1: 4)$ at $\mathrm{RT}$ followed by the addition of alkali (scheme 2). This gave a red precipitate which ran as a stable red spot by TLC with $\mathrm{Et}_{2} \mathrm{O}\left(\mathrm{R}_{\mathrm{f}}=\right.$ 0.8). It did not show any decomposition back into MB on the silica plate.

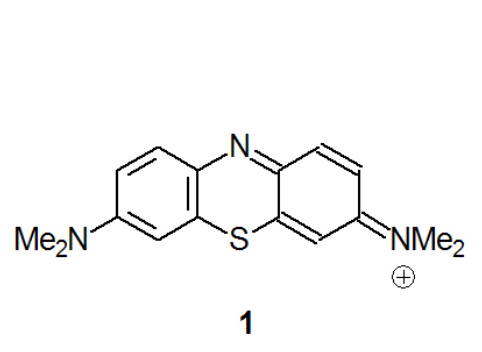<smiles>CNc1ccc(N(C)C)c(-c2c(N(C)C)ccc3nc4ccc(=O)cc-4sc23)c1</smiles>

5

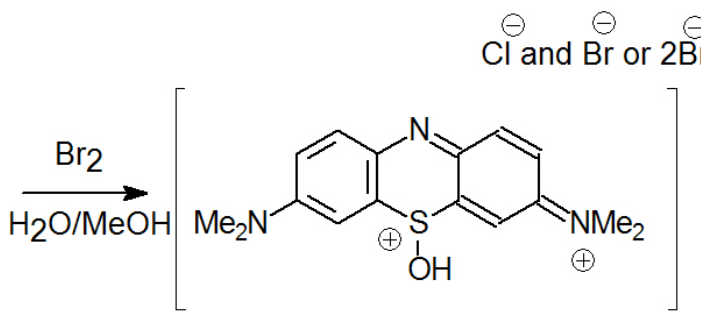

3

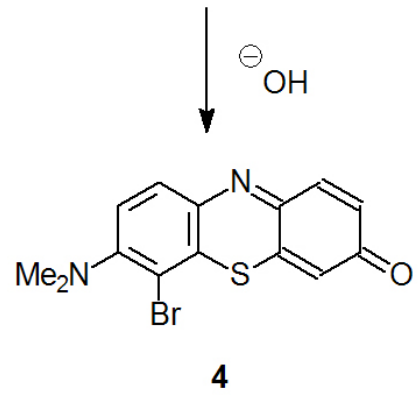

\section{Scheme 2}

The use of two equivalents of bromine gave the same product which shows that under these conditions the proposed sulphoxide is not readily oxidised further to the thermodynamically more stable sulphone group. The precipitate was extracted with $\mathrm{CH}_{2} \mathrm{Cl}_{2}$, dried over $\mathrm{K}_{2} \mathrm{CO}_{3}$ and 
purified by flash column chromatography eluting with $\mathrm{Et}_{2} \mathrm{O}$. Good ${ }^{1} \mathrm{H}$ NMR and ${ }^{13} \mathrm{C}$ NMR spectra were obtained of the product, which showed that the red compound was an asymmetric derivative of methylene violet. The ${ }^{1} \mathrm{H}$ NMR spectrum showed two pairs of coupled doublets and one singlet in the aromatic region. The methyl group protons $(6 \mathrm{H})$ occurred as a singlet at 3.0 ppm. The ${ }^{13} \mathrm{C}$ NMR spectrum gave 13 peaks. This data suggested a structure such as $\mathbf{4}$ or the dimer 5. ${ }^{17}$ The mass spectrum however showed a strong molecular ion peak at 334/336 characteristic of structure $\mathbf{4}$ and microanalytical data fitted closely for this compound. Compound 4 is much less polar than methylene violet (which lacks the bromine substituent) because the dimethylamino group is prevented from conjugating efficiently to the ring so the dye has a weaker dipole. This rules out the alternative isomer where the bromine is next to the carbonyl group, which would be polar like methylene violet.

The simplest mechanism for the formation of product 4 would involve electrophilic bromination of $\mathrm{MB}$ adjacent to the dimethylamino group. However treatment of $\mathrm{MB}$ with bromine, concentration to a solid in vacuo, then treatment with alkali and extraction with $\mathrm{Et}_{2} \mathrm{O}$ gave very little red product by TLC analysis. This shows that the aromatic ring was not functionalised by simple electrophilic bromination which might have been expected. Treatment of $\mathrm{MB}$ with premixed bromine and alkali was also unsuccessful. ${ }^{18}$ An alternative mechanism for the reaction is proposed in scheme 3.

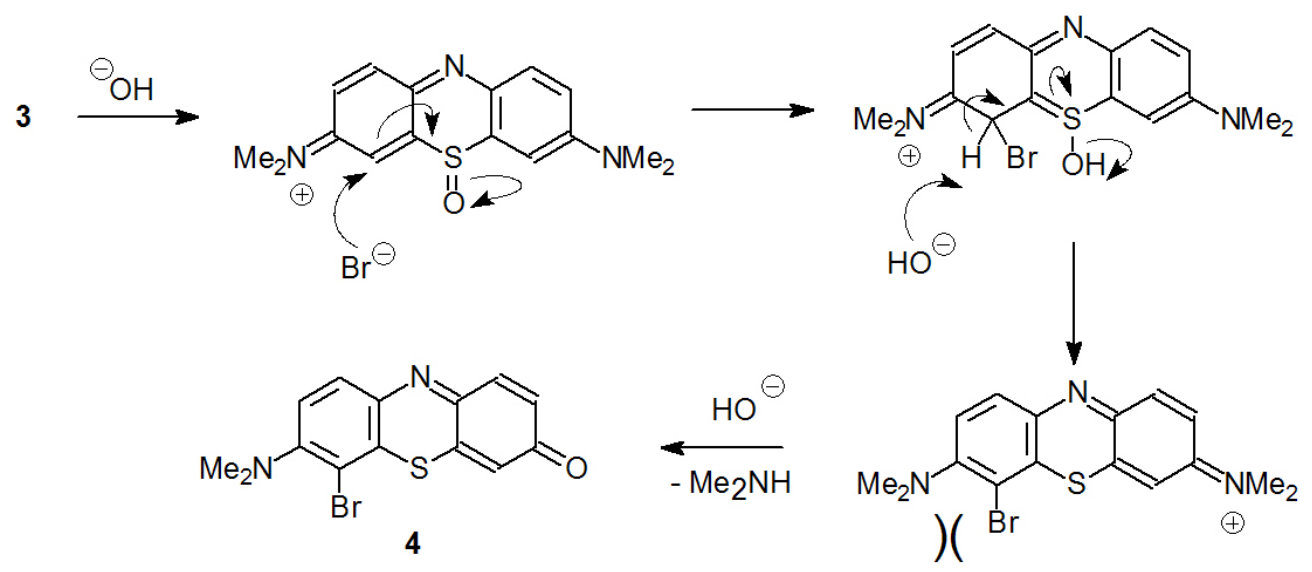

\section{Scheme 3}

This involves initial bromination of the sulphur atom and hydrolysis to give protonated Soxide $\mathbf{3}$ which is proposed as an intermediate in the reaction. The intermediate $\mathbf{3}$ does not rearrange in acid as might have been expected. When attempts were made to isolate it by removing the solvent in vacuo at $50-60{ }^{\circ} \mathrm{C}$ TLC analysis showed extensive decomposition mainly back into $\mathrm{MB}$. It might be unstable because it is doubly positively charged. Deprotonation of intermediate 3 gives the $S$-oxide of MB. This intermediate might spontaneously rearrange as shown to the product $\mathbf{4}$ under alkaline conditions. Equally well the bromine atom could attach to the sulphur atom and migrate via a 1,3-shift in basic media potentially making the reaction selective for bromide. Once the aromatic ring has brominated steric compression with the dimethylamino group reduces its conjugation to the positive charge favouring the canonical 
form shown. This is expected to selectively hydrolyse to give product 4 . The isolation of product $\mathbf{4}$ does not rule out hydroxide attack upon $S$-oxide $\mathbf{3}$ although the attachment of bromine to the dye must be quite efficient in the presence of hydroxide, which is unusual. An explanation for the reactivity of the $S$-oxide of MB is provided by SE calculations. ${ }^{19}$ The crystal structure of MB is perfectly planar yet calulations on the $S$-oxide show it to be strongly non-planar with the oxygen atom equatorial. The geometric requirement of the $S$-oxide, which can hold their conformation with their lone pair of electrons, is presumably straining the $\pi$-system and increasing the reactivity of the system. The bow shape occurs in related compounds such as thianthrenes. ${ }^{20}$ Thianthrene has an angle of $128^{\circ}$ between the two aromatic rings.

The red solid 4 is freely soluble in organic solvents and poorly soluble in water. Some of the solid was suspended in water at room temperature which remained clear to the naked eye. A quantity of water was drawn off through a filter in a pipette to prevent uptake of any undissolved material. The water was treated with a drop of acid which immediately turned it pale blue visible to the naked eye (scheme 4). Heating the solution also turned it blue. The solution turns clear or paler on cooling with an ice bath. The compound is solvatochromic being red in organic solvents but blue in water. The colour changes can be explained by hydration and dehydration of the quinoidal moiety although the hydrated form has not been isolated and its existence is not proven. A key structural feature however is the bromine substituent ortho to the $\mathrm{Me}_{2} \mathrm{~N}$ group which will reduce its ability to conjugate to the $\pi$-system thus making the quinoidal moiety more electrophilic. The UV spectrum also showed that the absorption at $660 \mathrm{~nm}$ increases in acid so this would also contribute to or explain the observed blue colouration upon acidification.

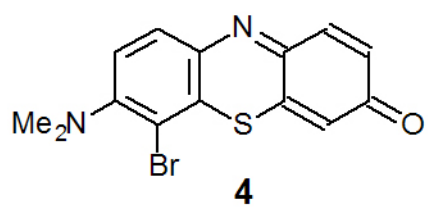

Blue in water

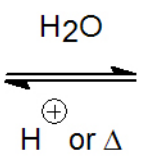

\section{Scheme 4}

Compound 4 absorbs at $660 \mathrm{~nm}$ but only in dil. $\mathrm{HCl}$ or warm water. Because it does not absorb at $660 \mathrm{~nm}$ in organic solvents it is probably not the leuco-dye MB observed previously. ${ }^{1-3}$ These observations do however suggest that compound $\mathbf{4}$ might be a leuco-base dye metabolite of MB. The author has obtained preliminary evidence that product $\mathbf{4}$ is a metabolite of MB in humans. The author experimented by ingesting MB then collecting and analysing urine samples. A compound of identical $R_{f}$ value and colour to product 4 was observed by TLC. Compound 4 presumably forms in humans under mildly basic conditions by the reaction of bromide ${ }^{21}$ with MB S-oxide which might be produced by oxidative metabolism. Previous studies determined blood bromide levels to be on average $5.3 \pm 1.4 \mathrm{mgL}$ with a range of 2.5 to $11.7 \mathrm{mgL}$ so enough bromide is present. ${ }^{22}$ Presumably MB and MB S-oxide may bind tightly to bromide which would facilitate the reaction. The use of $\mathrm{MB}$ as an antidote to cyanide and nitrate poisoning suggests 
that it is an anion binder. ${ }^{12}$ The production of the leuco-dye metabolite in humans follows a diurnal cycle with up to $80 \%$ of the dye MB excreted in urine as a leuco-dye during the daytime. ${ }^{2}$ The greater production of the leuco-dye during the daytime could occur as a consequence of the enhanced oxidative metabolism and oxygen consumption of the body which may cause greater quantities of MB to be oxidised. The same cycling may occur for the production of compound 4 described here.

Owing to the continuing interest in the biological activity of $\mathrm{MB}^{5}$ the understanding of its metabolism is of interest particularly because most of it can be excreted in one or more leuco-dye forms. ${ }^{1-3}$ Secondly, a medicine based on MB might be oxidised up to the S-oxide in vivo which will influence the drugs pharmacokinetics.

\section{Experimental Section}

General Procedures. NMR spectra were recorded on a Bruker $400 \mathrm{MHz}$ instrument. $J$ values are given in Hz. Infrared spectra were recorded on an ATI Mattson spectrometer with the sample prepared as a $\mathrm{KBr}$ disc. UV spectra were recorded on a Perkin-Elmer Lambda $15 \mathrm{UV}$-VIS spectrophotometer using ethanol as solvent. Mass spectra were obtained with a VG Quattro II triple quadrupole mass spectrometer. Melting points were measured using a Kofler hot-stage microscope and are uncorrected. Flash column chromatography was conducted using Kieselgel 60155728 P (Merck). Light petroleum refers to the fraction with bp $40-60{ }^{\circ} \mathrm{C}$.

Preparation of compound (4). $\mathrm{MB}(0.724 \mathrm{~g}, 1.94 \mathrm{mmol})$ in $\mathrm{MeOH} / \mathrm{H}_{2} \mathrm{O}(10: 40 \mathrm{ml})$ was treated with a stock solution of $\mathrm{Br}_{2}(5 \mathrm{ml})$ made up from $\mathrm{Br}_{2}\left(1 \mathrm{ml}\right.$ in $50 \mathrm{ml}$ of $\mathrm{H}_{2} \mathrm{O} / \mathrm{MeOH}$ 1:1) for $5 \mathrm{~h}$ at rt. The solution was then treated with saturated $\mathrm{NaOH}(10 \mathrm{ml})$ and more water $(100 \mathrm{ml})$ for 10 min then extracted with $\mathrm{CH}_{2} \mathrm{Cl}_{2}$, dried over $\mathrm{K}_{2} \mathrm{CO}_{3}$ and purified by flash column chromatography eluting with $\mathrm{Et}_{2} \mathrm{O}$. Yield $35 \%$ (227 mg); mp $186-189^{\circ} \mathrm{C}$ (from ether); $\lambda_{\max }$ (ethanol)/nm 536 (log $\varepsilon$ 3.66) and 276 (3.77), $\lambda_{\max }(\mathrm{dil} \mathrm{HCl;} 0.02 \mathrm{M}) / \mathrm{nm} 621$ (log $\varepsilon 3.29$ ), at $660 \mathrm{~nm}$ (3.04), $\lambda_{\max }$ (dil $\mathrm{HCl} ; 0.035 \mathrm{M}) / \mathrm{nm} 631 \mathrm{~nm}$ (3.59), at $660 \mathrm{~nm}(3.54) ;{ }^{1} \mathrm{H}$ NMR (400 MHz: $\left.\mathrm{CDCl}_{3}\right) 2.97$ (6H, s), $6.72(1 \mathrm{H}, \mathrm{s}), 6.83(1 \mathrm{H} \mathrm{d}, J$ 9.7), $7.09(1 \mathrm{H}, \mathrm{d}, J$ 8.9), $7.53(1 \mathrm{H}, \mathrm{d}, J 9.7)$ and $7.72(1 \mathrm{H}, \mathrm{d}, J$ 8.9); ${ }^{13} \mathrm{C}$ NMR 43.9, 111.8, 118.7, 119.8, 128.8, 134.0, 134.2, 135.5, 136.6, 139.0, 143.7, 154.4 and 182.6; (Found: C, 49.7; H, 3.5; N, 8.6. $\mathrm{C}_{14} \mathrm{H}_{11} \mathrm{~N}_{2} \mathrm{BrOS}$ requires $\mathrm{C}, 50.1 ; \mathrm{H}, 3.3 ; \mathrm{N}, 8.4 \%$ ); $\mathrm{m} / \mathrm{z}$ $334\left(\mathrm{M}^{+}, 100 \%\right)$ and $336\left(\mathrm{M}^{+}, 100\right) ; \mathrm{m} / \mathrm{z}$ Acc. $\mathrm{M}^{+} 333.9779 \mathrm{C}_{14} \mathrm{H}_{11} \mathrm{~N}_{2} \mathrm{BrOS}$ requires 333.9775. As the acid concentration increases the absorption at $660 \mathrm{~nm}$ increases linearly.

Metabolite Isolation. The author performed the following experiment. $10 \mathrm{mg}$ of MB was injested with plenty of water followed by the collection of urine for $48 \mathrm{~h}$. A sample of urine (4L) was treated with saturated $\mathrm{NaOH}(20 \mathrm{ml})$ and extracted once with $\mathrm{CH}_{2} \mathrm{Cl}_{2}(30 \mathrm{ml})$. The extract was evaporated and analysed by TLC with $\mathrm{Et}_{2} \mathrm{O}$ as eluent. A blue baseline spot was apparent and a red spot of identical $R_{f}$ value and colour to compound 4 . As the plate dries out both spots change colour in an identical manner to a blue/red hue also showing that the same chromophore is present. Otherwise the plate was very clean visibly and in the UV. This experiment confirms 
the formation of product 4 as a metabolite of MB. Treatment of the urine with alkali prevents extraction of acidic urinary constituents but is not essential to observe compound 4 .

\section{References and Notes}

1. DiSanto, A. R.; Wagner, J. G. J. Pharm. Sci. 1972, 61, 598.

2. DiSanto, A. R.; Wagner, J. G. J. Pharm. Sci. 1972, 61, 1086.

3. DiSanto, A. R.; Wagner, J. G. J. Pharm. Sci. 1972, 61, 1090.

4. Gurr, E. Staining-Practical and Theoretical 2nd Edition, Williams and Watkins, Baltimore, Md., 1962, pp 303.

5. Wischik, C. M., WO 96/30766 Filing date 25.03.96.

6. Dreser, H. Z. Biol. 1885, 21, 41.

7. Muller, F. Deut. Arch. Klin. Med. 1899, 53, 130.

8. Elsner, K. Deut. Arch. Klin. Med. 1901, 59, 47.

9. Herter, P. Am. J. Physiol. 1904, 12, 128.

10. Underhill, F.; Closson, O. Am. J. Physiol. 1905, 13, 358.

11. Griffiths, R. Prog. in Neurobiol. 1990, 35, 313.

12. Methylene blue is an antidote to both cyanide and nitrate poisoning, The Merck Index, 11th edition, pp 5979. It presumably acts by anion binding followed by excretion.

13. Breslow, R. Chem. Ind. (London) 1956, R28.

14. The central nitrogen of methylene blue can be acetylated by treatment with zinc dust then acetic anhydride. Obata, H. B. Chem. Soc. Jap. 1961, 34, 1057; Cohn, G. Ber. 1900, 33, 1567.

15. The author has observed by TLC the formation of methylene violet as the major degradation product of MB with alkali (see ref. 16)

16. For some early studies on the oxidation and hydrolysis of methylene blue see Bernthsen, $A$. Ber. 1906, 1804; Bernthsen, A. Annalen 1885, 230, 169 and 211; Conn’s, H. J. Biological Stains, ed. Lillie, R. D., Pub. Williams and Wilkins, Baltimore, 9th edition, 1977, pp 493502.

17. From the baseline in the aromatic region the presence of another compound with a similar ${ }^{1} \mathrm{H}$ NMR spectrum was apparent.

18. Bromine reacts rapidly with alkali to give bromate $\mathrm{BrO}_{3}$, Merck Index, 11th edition, pp 1358.

19. Rzepa, H. personal communication.

20. Hosoya, S. Acta Cryst. 1963, 16, 310.

21. Treatment of MB with bleach (12\% w/v chlorine) then alkali gives a slightly more polar but weaker red spot by TLC analysis characteristic of the chlorine analogue of $\mathbf{4}$. Treatment of MB with I-Cl then alkali gave no red product.

22. Olszowy, H. A. J. Anal. Tox. 1998, 22, 225. 